\title{
An Analysis of English Schooling at College Quality Based on Modern Information Technology
}

\author{
Wenhui Wang and Hua Zhang $(D$ \\ School of Foreign Languages, Weifang University, Shandong,261061, China \\ Correspondence should be addressed to Hua Zhang; zhanghua198316@126.com
}

Received 21 December 2021; Revised 8 January 2022; Accepted 10 January 2022; Published 4 March 2022

Academic Editor: Tongguang Ni

Copyright (c) 2022 Wenhui Wang and Hua Zhang. This is an open access article distributed under the Creative Commons Attribution License, which permits unrestricted use, distribution, and reproduction in any medium, provided the original work is properly cited.

\begin{abstract}
The importance of learning English is increasing as China's foreign exchanges become more frequent. China's independent colleges have been steadily growing in recent years, with the main school's main characteristic of cultivating applied talents, and teaching quality gradually improving. College English teaching is a practical application of college English education and instruction. The "sum of beliefs, recognized values, and technologies commonly accepted by the members of a specific community" is the world outlook and mode of behavior that a group of researchers engaged in a particular science adopts. Modern information technology has pervaded people's work and lives since the dawn of the information age, and it is now widely used in a variety of fields. Teachers' primary roles have shifted from disseminator of information, presenter of knowledge, transmitter of culture, and provider of correct answers in today's learning environment supported by modern information technology to promoter of learning, organizer of activities, student helper, and interactive collaborator. This paper obtains some information useful to the development of teaching work based on the data mining algorithm used in the mining practice of the educational administration information management system. This information is useful for improving teaching quality, implementing the talent development program more effectively, mastering student skill development, and teachers' teaching situations.
\end{abstract}

\section{Introduction}

With the increasingly frequent foreign exchanges in China, the importance of English learning is becoming more and more prominent. In recent years, China's independent colleges have developed continuously, with the main school running characteristics of cultivating applied talents, and the schooling quality has been gradually improved [1]. Since the 1990s, English schooling at college units in many Chinese universities have successively launched the schooling quality assurance system. Its main purpose is to improve schooling measures and promote the improvement of schooling quality through continuous schooling quality monitoring. English schooling at college is a specific application in the field of English schooling at college education and schooling [2]. In addition, teachers in independent colleges and universities have many courses and great teaching pressure. Many teachers do not have much energy to design an interesting, interactive and diverse English class. In addition, students are not easy to learn. As a result, many teachers teach according to the book, the teaching form is single, the content is boring, and cramming teaching, which finally make teachers become "lonely speakers" who entertain themselves on the podium. The world outlook and behavior mode that researchers engaged in a certain science follow together is "the sum of beliefs, recognized values and technologies accepted by members of a specific community" [3]. First, the data set is divided into training data set and test data set. First, the training data set is used to construct the model by analyzing the database tuples described by attributes. This stage is also a learning stage. The generated model is expressed in the form of classification rules, mathematical formulas, or decision trees. However, there are still many problems in English schooling at college in independent colleges: students' weak foundation, incorrect learning attitude, poor autonomous learning ability, serious shortage of 
teachers, unreasonable teacher structure, old and boring schooling mode, serious shortage of schooling hardware, and so on. The evaluation index of schooling quality is an important basis of schooling quality assurance system. The existing evaluation indicators mostly adopt the comprehensive evaluation method, and its index system is usually composed of multilevel indicators $[4,5]$.

Schools, as the output platform of future talents, should have this forward-looking vision as the universal development of modern information technology marks the rise of global economic integration, closer multilateral cooperation among countries, and continuous improvement of international exchanges. Traditional schooling activities usually only involve teachers, students, schooling materials, and other basic elements, but modern schooling also includes the element of "modern information technology" $[6,7]$. This method of assessing educational quality is widely used and has produced some results. Traditional methods of evaluating educational quality, on the other hand, are not without flaws. Teachers' primary roles in the learning environment supported by modern information technology have shifted from information disseminators, presenters of knowledge, transmitters of culture, and providers of correct answers to promoters of learning, organizers of activities, student helpers, and interactive collaborators $[8,9]$. This paper uses modern information technology to examine the educational quality of English schooling at the college level in order to serve as a model for future large-scale English schooling implementation at the college level. It is not only possible but also necessary to use modern information technology to assist English schooling in college, and it is an unavoidable requirement for developing innovative talents. English as a language subject has gotten a lot of attention in the process of using modern information technology to innovate traditional education $[10,11]$ because of its unique communication and practicality.

Assisted by modern information technology, higher vocational schooling can add advantages to traditional schooling, such as strong interaction, large amount of information, strong real-time, diverse media, and rich forms, which have a great positive impact on language learners' mastery of listening, speaking, reading, writing, and translation in English schooling at college and the cultivation of autonomous learning ability, At the same time, English schooling at college reform and English teachers are facing new challenges and opportunities [12]. In order to comprehensively, objectively, scientifically, and accurately evaluate the quality of English schooling at college based on modern information technology, the combination of formative evaluation and summative evaluation should be adopted, and the evaluation procedure should be standardized to ensure the reliability and validity of the evaluation [13]. Students cannot understand the charm of English, cannot have interest in English schooling at college quality, and cannot improve their English level. The data of teachers' teaching evaluation cover a wide range and has qualitative attributes, such as students' overall evaluation. There are also some quantitative attributes, which are relatively few, such as students' evaluation of teachers' teaching content. Data mining algorithm has good efficiency and effect in dealing with discrete data. Before data mining, data can be discretized in advance. Of course, data mining algorithm can also deal with continuous data. Teachers can carefully design and organize schooling through schooling software and network resources to truly play the leading role of teachers [14]. Different from audiovisual schooling means, the application of modern information technology characterized by multimedia and network requires teachers not only to master information application technology, such as word processing and operation skills, but also to learn to use some corresponding schooling software. Modern information technology assisted English schooling at college is a schooling method to cultivate students' comprehensive ability [1]. On the other hand, although multimedia schooling has changed in schooling form, it cannot be separated from the role of teachers' guidance.

\section{Related Work}

According to literature [15], when English schooling at college goes global, it will be localized, and localization of English schooling at college is an unavoidable result of globalization. According to literature [16] literature, the number of college students in China has risen sharply as a result of the continuous expansion of university enrollment, but English teachers are becoming increasingly tense, which has led to the continuous expansion of class size, with some colleges and universities having more than 100 students in a class. This will inevitably result in fewer language communication activities between teachers and students, resulting in a continued decline in schooling efficiency and quality in English classrooms. Data mining has been facing the application field of solving practical problems since it was proposed, according to literature [17], and its scope is very broad, involving almost all economic and social industries, including economic management, finance, insurance, electric power, astronomy, petrochemical, biology, geography, geology, and so on. According to literature [18], traditional English schooling at college is facing severe challenges due to the application of computer network technology and the development of English network resources. According to literature [19], it can be seen that the development of society promotes homogeneity on the one hand, and the school education theory and its elements are interconnected and further strengthened; on the other hand, the strengthening of localized knowledge and research makes foreign language education present heterogeneity and diversity, which is the interaction of globalization and localization of English education in the university paradigm. Literature [13] research shows that students' English learning materials are very rich, and their learning methods are increasingly diversified. Various English learning websites, audio materials, and multimedia software emerge one after another. Many English schooling at college textbooks are also equipped with CD-ROMs, such as new English schooling at college and new practical English. Literature [20] puts forward that from the perspective of the law of 
language schooling itself, each country and region has its own unique "localized" language schooling policy, schooling path, schooling approach and schooling method, and has its own unique local culture, language habits, thinking mode and the "migration" interference of mother tongue. Literature [21] through the big data analysis method, as a kind of human cognitive practice, school education activities have a complex interactive relationship among teachers, students, and content. Compared with "school education," teachers are the undertaker and subject of activities, and students are the object and object of teachers' work. Literature [22] studies show that in the face of the wave of globalization, especially the convergence of educational technology development, educational exchanges between the East and the West are also deepening. The globalization trend of foreign language schooling has become inevitable, which is mainly reflected in the diffusion and integration of schooling theories, the international sharing of educational resources, and the development of English schooling at college materials and schooling resources towards a more international trend. Literature [23] pointed out that the application and popularization of network technology are making China form a brand new network society. People's working methods and learning environment have undergone great changes, and it is entirely possible to realize "lifelong education" and "national learning."

Based on the data mining algorithm in modern information technology, this paper analyzes the quality of college English teaching, designs learning tasks, mobilizes learners' potential, provides scaffolding activities for learners, carries out data mining for learners, and gives guidance, feedback, and evaluation on the problems encountered in the learning process.

\section{Construction of Algorithm Model for English Schooling at College Quality Analysis}

3.1. Data Mining Principle and Algorithm. The data mining algorithm is a global and parallel search optimization algorithm. Students are the initiator and subject of activities, whereas schooling content is the object and object of activities, as opposed to "learning." The following are some of the meanings of this definition: Massive, real-time, and noisy data sources are required; what they uncover is knowledge that is relevant and interesting to users. And the knowledge that is discovered must be understandable, acceptable, and useable; finding universal knowledge is not required, but only supporting specific problems is. When solving optimization problems, data mining algorithms have the problem of searching for the best solution slowly, which is frequently accompanied by premature convergence. According to the advantages of randomness and stable tendency of cloud droplets in cloud model, conditional cloud generation algorithm and basic cloud generation algorithm are adopted to realize crossover and mutation operations, accelerate the search ability, keep the random search, and adaptively adjust the crossover and mutation probability to prevent falling into local optimum defects. The data mining algorithm adopts B/S structure (browser/server, browser/server mode), the server side stores applications and related databases, and customers access the server through the browser. The flow structure of data mining algorithm is shown in Figure 1.

For training sample set $\left\{\left(x_{i}, y_{i}\right)\right\}, i=1,2, \ldots, n$, $x_{i} \in R^{n}, y_{i} \in R$. $\mathrm{Xi}$ and $\mathrm{Yi}$ are the evaluation index of classroom schooling quality and the output value of classroom schooling quality respectively, which are fitted by the following formula

$$
y=w^{T} \cdot x+b
$$

where $\omega$ is the weight vector and B is the offset.

According to the principle of structural risk minimization, the SVM regression model for solving the problem of (2) is

$$
\min \frac{1}{2} \omega^{T} \omega+C \sum_{i=1}^{n}\left(\xi_{i}+\xi_{i}^{*}\right)
$$

Constraints are

$$
\left\{\begin{array}{l}
y_{i}-\omega^{T} \cdot x_{i}-b \leq \varepsilon+\xi_{i}, \\
\omega^{T} \cdot x_{i}+b-y_{i} \leq \varepsilon+\xi_{i}^{*}, \\
\xi_{i}^{*} \geq 0, \xi_{i} \geq 0
\end{array}\right.
$$

where $c$ is the penalty parameter and $\varepsilon$ is the fitting accuracy between the actual value and the regression function. Using duality theory, the (3) is transformed into a quadratic programming problem, namely

$$
\begin{aligned}
L(\omega, b, \xi, \alpha)= & \frac{1}{2} \omega^{T} \omega+C \sum_{i=1}^{n}\left(\xi_{i}+\xi_{i}^{*}\right) \\
& +\sum_{i=1}^{n} \alpha_{i}\left(\omega^{T} \phi\left(x_{i}\right)-b+\xi_{i}-y_{i}\right),
\end{aligned}
$$

where $\alpha_{i}$ is Lagranse multiplier.

For the nonlinear classroom schooling quality evaluation problem, the classroom schooling quality training samples are mapped to the high-dimensional feature space through the nonlinear mapping function $\phi(\cdot)$, and the linear regression is carried out. The nonlinear SVR model is

$$
y=\sum_{i=1}^{n}\left(\alpha_{i}^{\bullet}-\alpha_{i}\right) K\left(x_{i}, x\right)+b,
$$

where $K(X i, x)$ represents the kernel function.

Let $X i, X J \in u$ be described as $X i=\{X i, 1, X i, 2, \ldots, X i, m\}$, $X J=\{X J, 1, X J, 2, \ldots, X J, m\}$, then the difference measurement formula for simple matching between $X i$ and $X J$ is

$$
d\left(x_{i}, x_{j}\right)=\sum_{l=1}^{m} \delta\left(x_{i, l}, x_{j, l}\right) .
$$

Among

$$
\delta\left(x_{i, l}, x_{j, l}\right)= \begin{cases}1, & x_{j, l} \neq x_{i, l}, \\ 0, & x_{j, l}=x_{i, l} .\end{cases}
$$




\begin{tabular}{|c|c|c|c|c|}
\hline \multirow[b]{2}{*}{ Data fusion } & Request & \multirow[b]{2}{*}{ Data analysis } & Request & \multirow{2}{*}{$\begin{array}{c}\text { Decision } \\
\text { support }\end{array}$} \\
\hline & & & & \\
\hline
\end{tabular}

FIgURE 1: Flow chart of data mining algorithm.

Let $X=\{X 1, X 2, \ldots, X n\}$ be a group of data objects, where $X=(x i 1, x i 2, \ldots, x i m)$ represents a data object with $m$ attribute values. Use "mode" to represent this set of data objects, and the mode of $x$ is defined as $Q=\left(q_{1}, q_{2}, \ldots, q_{m}\right) \in U$ so that

$$
D(X, Q)=\sum_{i=1}^{n} d\left(X_{i}, Q\right)
$$

Get the minimum.

Data mining is a method that evolves over time. Data mining, on the other hand, is discovery-driven in that patterns are automatically extracted from data through a lot of searching work. Traditional data analysis methods generally give a hypothesis first and then pass the data verification, which is hypothesis-driven in a sense.

\subsection{Analysis Model of English Schooling at College Quality} Based on Data Mining Algorithm. Many studies have found that when solving a data mining algorithm, the speed of finding the best solution is slow, and that this is frequently accompanied by premature convergence. The conditional cloud generation algorithm and the basic data mining algorithm are used to realize crossover and mutation operations, accelerate optimization ability, and maintain the randomness of search, according to the randomness and stability tendency of the data mining algorithm. The crossover and mutation probabilities are adaptively adjusted to avoid falling into the defect of local optimization. Educational data mining and learning analysis are the two main directions of big data research in the field of education. Because many independent colleges and universities use the final English score and English schooling at College-4 pass rate of each semester to measure teachers' schooling level, most teachers focus on how to improve students' English schooling at College-4 pass rate and examination pass rate, ignoring English schooling itself. The relationship between educational data mining, learning analysis, and English schooling at college, pedagogy, and schooling quality is shown in Figure 2.

Data mining is an important means of data utilization under the background of big data, which refers to the process of extracting effective, novel, and potentially useful data from a large number of data and utilizing understandable knowledge, models and rules. The data mining algorithm is used to optimize the English schooling at College quality analysis model, and the optimization process is shown in Figure 3.

(1) Select the evaluation index of English classroom schooling quality.

(2) Collect the historical data of English classroom schooling quality evaluation, process the data, and eliminate some useless data.

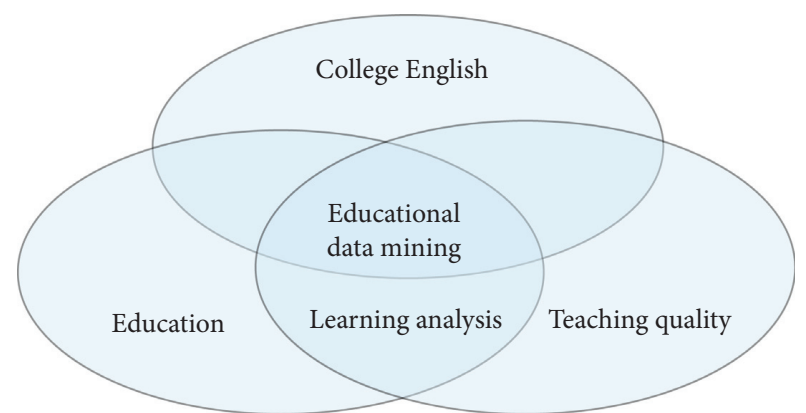

FIgURE 2: Major disciplines involved in data mining and schooling quality analysis of English schooling at College.

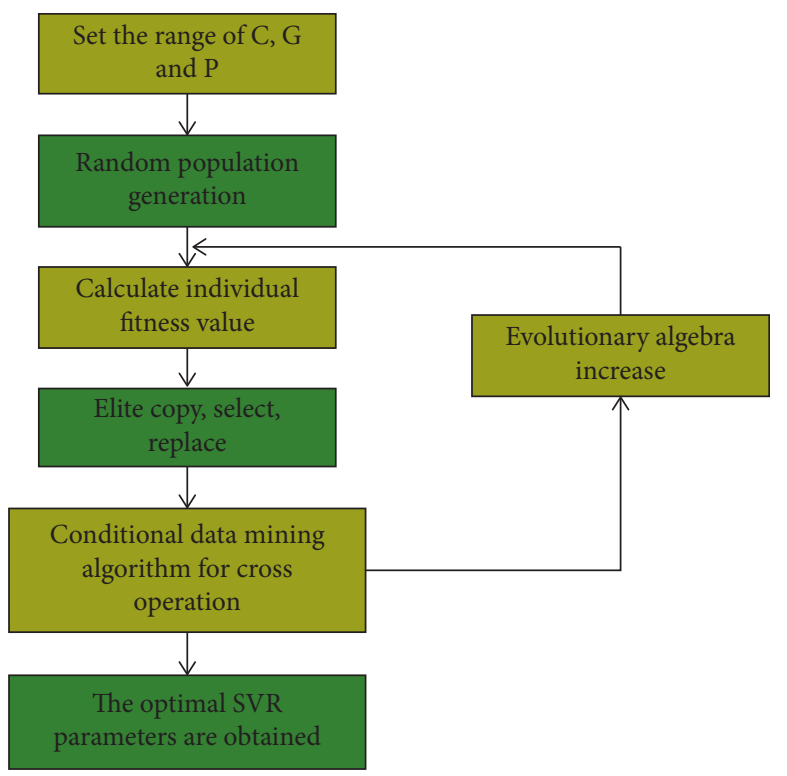

FIgURE 3: Optimization of English schooling at College quality analysis model based on data mining algorithm.

(3) In order to speed up the learning of SVR, the evaluation index values of English schooling at College quality are normalized. The specific normalization formula is as follows:

$$
x_{i}^{\prime}=\frac{x_{i}-x_{\min }}{x_{\max }-x_{\min }}
$$

where $x_{\max }$ and $x_{\min }$ represent the maximum and minimum values of each evaluation index, $\mathrm{Xi}$ and $\mathrm{x}$ ' $\mathrm{i}$. Represent the values before and after normalization, respectively.

After processing the data by formula, the range of all indicators is $[0,1]$, which can improve the efficiency of the English schooling at College quality analysis model.

(4) Divide the processed and normalized data into two parts: training sample set and test sample set. Input the training samples into SVR for training. In the training process, use data mining algorithm to optimize the English schooling at College quality analysis model. 
(5) Get the optimal parameters and learn the training samples again with the optimal parameters, so as to establish the optimal evaluation model of English classroom schooling quality.

(6) Test the performance of the established optimal evaluation model of classroom schooling with test sample set, so as to realize the automatic evaluation of English classroom schooling quality.

\section{Analysis and Application of English Schooling at College Quality Based on Modern Information Technology}

\subsection{Application of Data Mining in English Schooling at College} Quality Analysis. English schooling at College inherits the benefits of schooling, the most notable of which is high schooling efficiency, which can help to alleviate China's shortage of high-quality talent and meet the needs of national modernization to some extent. As a college public English teacher, we should help students expand their English knowledge, broaden their horizons, and gain a more comprehensive understanding of the quality of English schooling and learning on the basis of a nine-year compulsory education. Data mining has been oriented to the application field to solve practical problems since its inception, and its scope is extremely broad, encompassing almost every industry in the economy and society, including economic management, finance, insurance, electric power, astronomy, and the petrochemical industry. Biology, geography, and geology are three fields of study. Schooling activities, as one of the human cognitive practice activities, have a complex interaction and relationship between teachers, students, and content. Compared with "schooling," teachers are the undertaker and subject of activities, while students are the object and object of teachers' work. Compared with "learning," students are the undertaker and subject of activities, and schooling content is the object and object of activities. However, because many independent colleges and universities take the final English score and English schooling at College-4 pass rate of each semester as the standard to measure teachers' schooling level, most teachers focus on how to improve students' English schooling at College- 4 pass rate and examination pass rate, thus ignoring the schooling of English itself. Students cannot understand the charm of English, cannot have interest in English schooling at College quality, and cannot improve their English level. Domestic enterprises applying data mining are led by communication enterprises (China Mobile, China Unicom and China Telecom), and the depth and breadth of application are in a leading position. Domestic banks, insurance companies, and securities companies are also more willing to use data mining technology, which is consistent with the international trend. In the next few years, the application of data analysis in the financial field will definitely develop from traditional statistical analysis to large-scale data mining application.

Due to the large number of students, there are significant differences between students in basic English knowledge and language application ability in the analysis of English schooling at College quality, making it difficult for teachers to accurately grasp the "degree" of schooling requirements in the process of schooling quality analysis. The use of data mining technology by search engine companies is also in high demand. They must employ data mining algorithms to discover the structural and association relationships between web pages in order to better push web pages. In order to maximize commercial profit, major search engines must increase advertising revenue and analyze click stream data.

If schooling is conducted strictly according to schooling requirements, it will put a significant number of students with a weak foundation and lack of ability under psychological stress, causing them to experience excessive anxiety, tension, inferiority, disappointment, weariness, and other emotions. This group of students will eventually stop learning English at a college level. The majority of these students believe that their English learning is inadequate, and even worse, that they are tired of learning, believing that everything will be fine as long as they pass the final exam. Large class schooling of English at College quality still follows the traditional schooling mode, with the schooling goal of mastering language knowledge, the schooling content of words and sentences and discourse analysis, the schooling method of explanation and translation, and a limited ability and energy of teachers due to large class size, unsatisfactory schooling environment, obvious differences in students' levels, and limited ability and energy of teachers. Independent colleges and universities, on the other hand, have no shortage of studious students, and their attitude toward class is correct. Poor English foundation, low learning autonomy after class, quick success in learning English, and a strong purpose are some of their common issues. They want to pass the final exam and complete their English education at College-4, but they refuse to study hard and apply the teaching methods and skills.

4.2. Experimental Results and Analysis. Before the experiment, this paper trains the English schooling at College quality analysis model through 55 training sets. For each training composition, this paper should preprocess it, including segmentation, word segmentation, sentence segmentation, part of speech tagging and dependency parsing. In this paper, $5,10,15, \ldots, 55$ English compositions were used for training, and a total of 20 models were trained. The performance of these 20 models was analyzed by using the above experimental evaluation criteria. The experimental results are shown in Figure 4 . With the increase of the number of samples, the overall trend of accuracy, recall and $F$ value also increases.

Secondly, through a group of comparative experiments, this paper tests the data mining algorithm and Soon's method on the same test set, and analyzes the advantages and disadvantages of this data mining algorithm. Our test set contains 30 English compositions written by Chinese students, of which there are 1420 entities in total.

The experimental results are shown in Figure 5. On the test set, son's model has accuracy, recall, and $F$ values of 


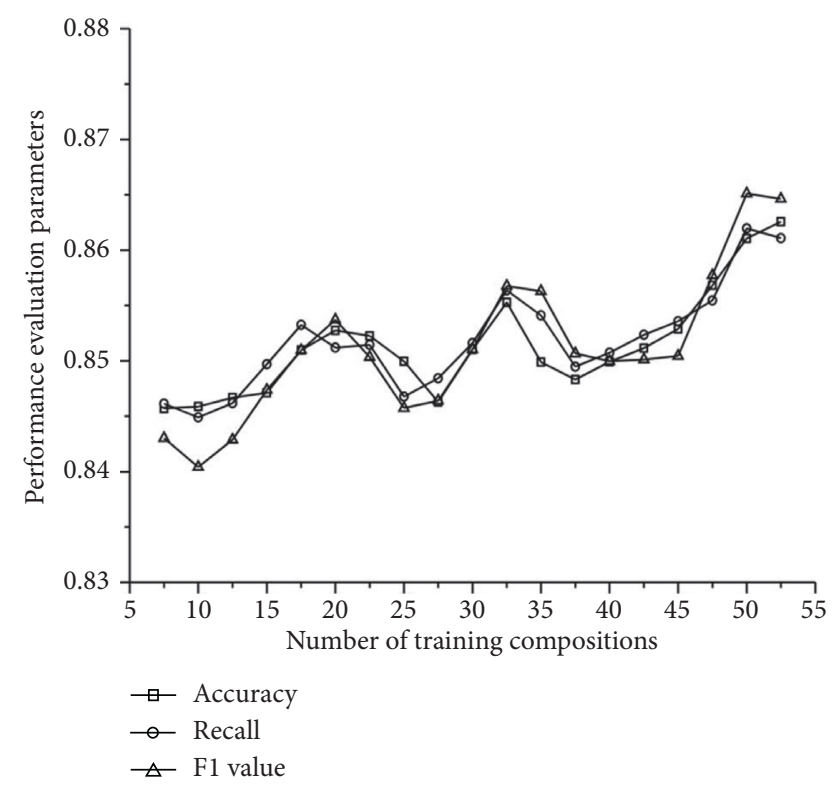

FIgURE 4: The change trend of accuracy, recall and F value with the increase of sample number.

$0.804,0.79$, and 0.77 , respectively, whereas the data mining algorithm model in this paper has accuracy, recall, and $F$ values of $0.898,0.899$, and 0.895 , which are all better than son's model. This also shows that selecting the right features and adding useful ones can help the data mining algorithm model perform better. Furthermore, the data mining algorithm model in this paper incorporates English schooling at College quality as an external knowledge source, allowing for the discovery of more co referential relationships of English schooling at College quality and an expansion of the co referential resolution range of the soon model.

Because Soon's method is a general method, that is to say, Soon's method may be effective in many fields, the performance of Soon's method on this test set is also better than that on MUC-6 and MUC-7 test sets. However, after feature extraction method optimization and feature design optimization, this data mining algorithm model has evolved into a more targeted co-reference resolution model in the application field, and it has more advantages in the field of English composition than Soon's model.

This study employs a data mining algorithm to construct a prediction model for English schooling at College- 4 pass probability of English schooling at College quality analysis of our students by adding modeling attributes and adjusting model parameters in the data mining environment of SPSS modeler, based on students' basic information, English schooling at College quality analysis course scores, and various grade examination scores. By double-clicking on the prediction result node, you can see how important each attribute is. The importance value of each attribute is shown in Figure 6.

The most important factor in passing English schooling at College-4 prediction is "English schooling at College final grade average." The main reason is that the English schooling quality at College is similar to the requirements of English schooling at College-4, and the question types and

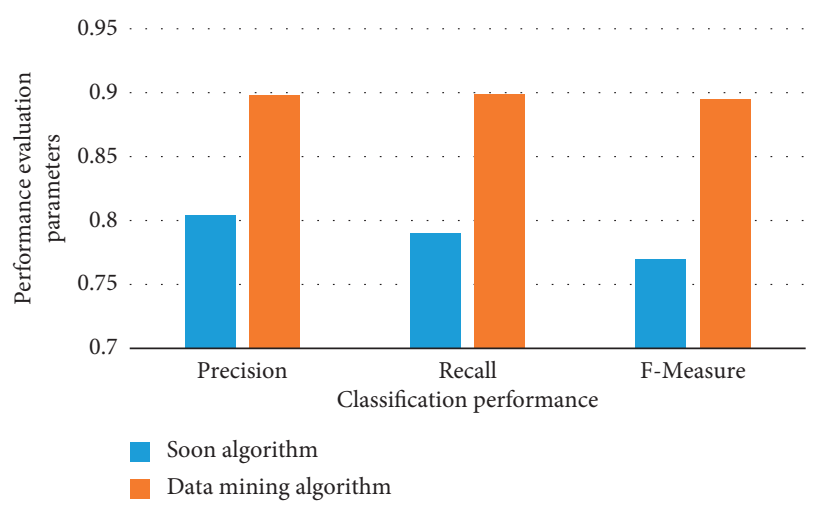

Figure 5: Performance comparison between data mining algorithm and Soon algorithm.

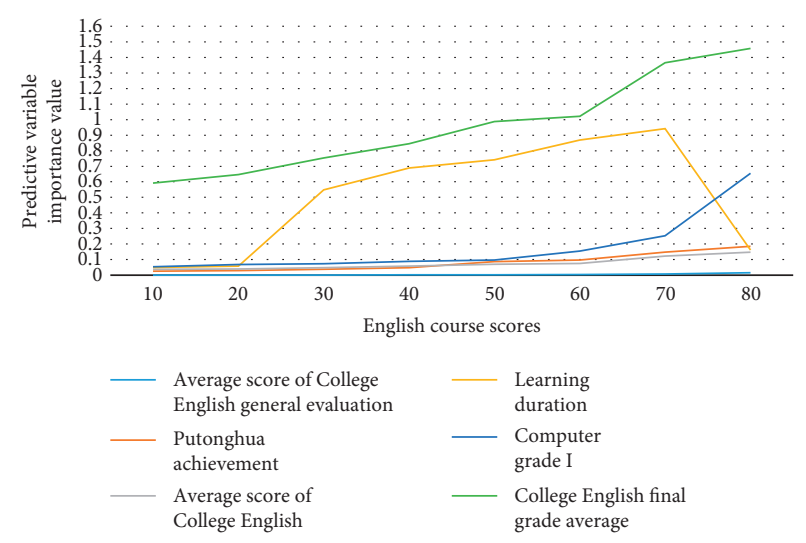

FIGURE 6: Importance value of each predictive variable.

questions are nearly identical. Both are written examinations that use answer cards to complete questions, according to the examination form. Both the students' knowledge level and examination mentality are taken into account. As a result, if the analysis of English schooling at College quality yields positive results, the likelihood of passing English schooling at College4 will naturally increase, as shown in Figure 7.

The pass rate and average score of English schooling at College 4 are higher for girls than for boys, according to the analysis of the data samples in the figure. The "learning duration" attribute indicates that the length of the learning period has an effect on whether students pass English schooling at College-4. The number of Public English schooling at College semesters for students in grades 2014, 2015, and 2016 is 4 semesters, 3 semesters, and 2 semesters, respectively, according to the school's training programs, and students are not permitted to apply for English schooling at College- 4 in the first semester. The data show that during the first semester of an English schooling at College course, the number of English schooling at College- 4 students can remain in the three digits, and that the number of English schooling at College-4 students drops sharply after the course, as shown in Figure 8.

It was discovered in a survey of college students' independent learning of English schooling at College quality analysis that "Only 42.5 percent of students can commit to 


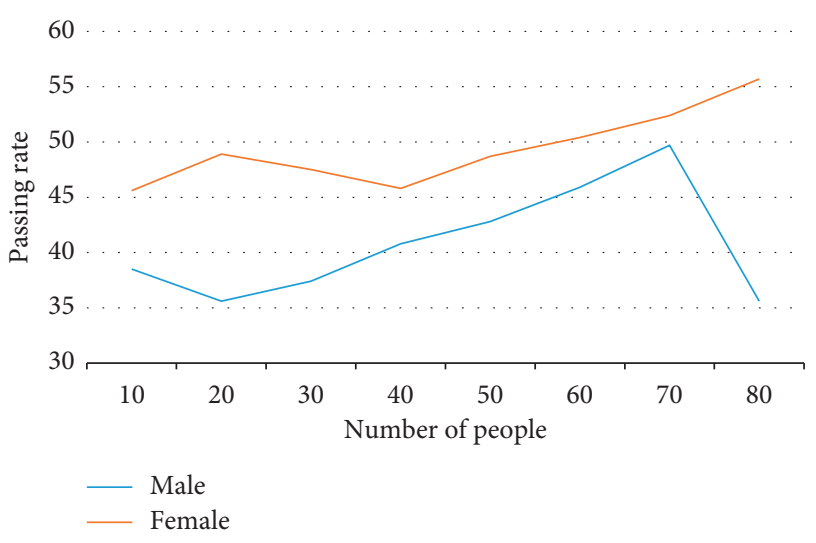

Figure 7: Pass rate of English schooling at College-4 for male and female students.

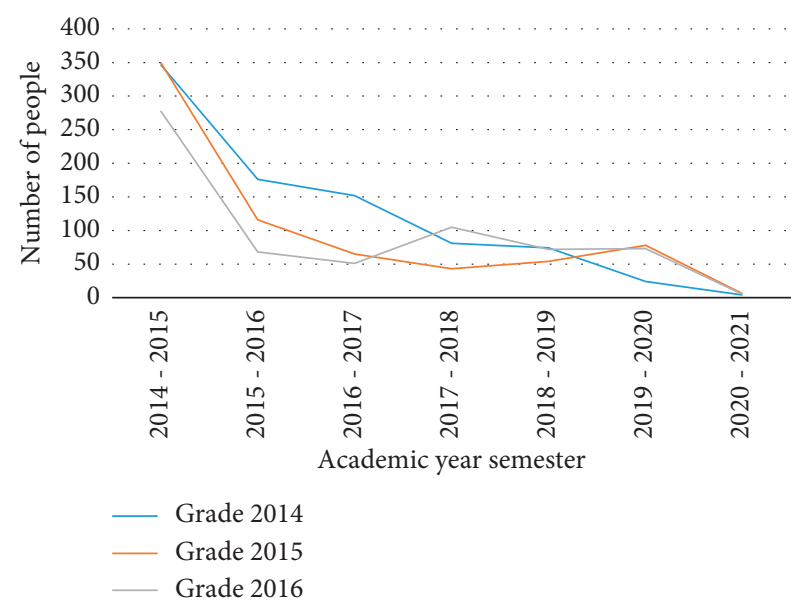

FIGURE 8: Statistics of the number of students passing English schooling at College- 4 in each academic year and semester.

4-6 hours of study time per week, and less than $15 \%$ can commit to more than 7 hours of study time. Every day, students spend approximately half an hour studying English schooling at College quality analysis." We can see that during the 110 days from March 10th, 2020, to June 28th, 2020 (excluding May Day holiday), online class students spent an average of more than one hour per day on online self-learning, indicating that online English schooling at College quality analysis has played a positive role in stimulating students' learning motivation and enhancing students' self-learning ability, as shown in Figure 9.

At the end of the first semester of the online class, the average scores of each item were $15.5,30.4,10.3,8.6$, and 8 , respectively, which were $1.2,1.7,1.2,2.1$, and 0.6 points higher than those of the non-online class. At the end of the second semester, the average scores of online classes were 16, $32.2,12.2,8,8.6$, respectively, which was $2.5,2.6,2,1.6,0.2$ higher than that of non-online classes. The difference of scores shows that students in online classes have steadily improved their English learning scores under the network English schooling at College environment, and the speed of improvement is higher than that of non-online classes, as shown in Figure 10.

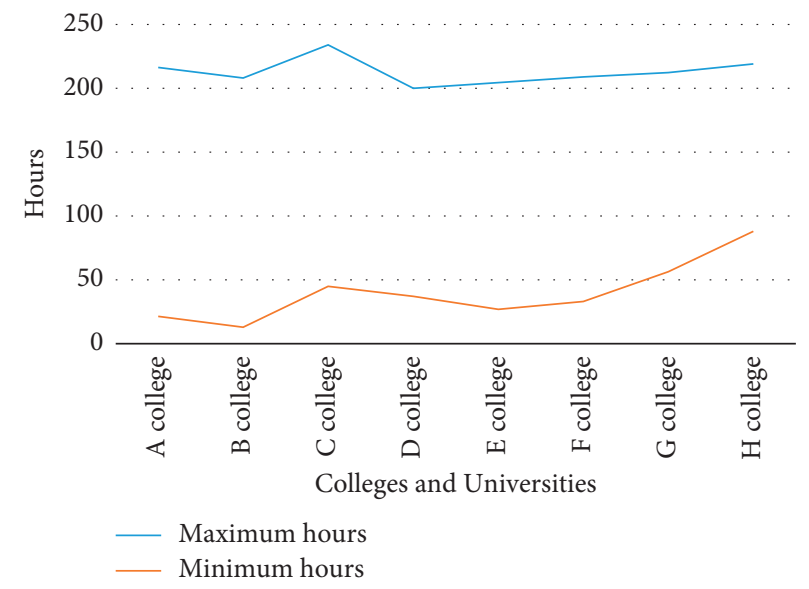

FIGURE 9: Statistics of autonomous learning hours of online English schooling at College for 2020 online class students.

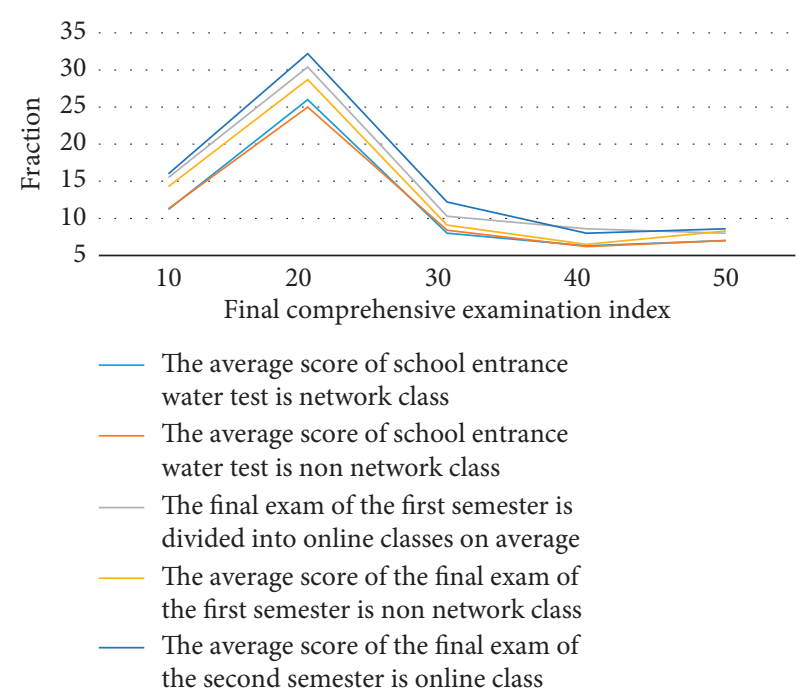

FIgURE 10: Comparison of scores of 2020 online class and nononline class.

\section{Conclusions}

In today's rapidly changing society and market, data mining technology provides us with methods and means that are unquestionably useful for making decisions. From the perspectives of the evaluation system, teaching mode, and teaching practice, this paper examines the role of networkbased college English teaching mode in improving college English teaching quality. We have mastered the use principle of data mining algorithms and the realization of mining through research and practice and have implemented a data mining process using data mining tools. This allows us to gain a better understanding of data mining and lays a solid foundation for future research on the quality of college English teaching and data mining in our work. Educational data mining and analysis methods are becoming more common as educational data mining research advances, and the value of traditional educational data will be rediscovered. As a result, mining large amounts of traditional data is more 
likely to uncover deep-seated rules of college English development, teachers' teaching, and students' learning, among other things, which will aid in improving college English teaching quality analysis, improving teaching quality, and promoting students' learning.

\section{Data Availability}

The data used to support the findings of this study are included within the article.

\section{Conflicts of Interest}

All the authors do not have any possible conflicts of interest.

\section{References}

[1] X. Li, "Characteristics and rules of college English education based on cognitive process simulation," Cognitive Systems Research, vol. 57, pp. 11-19, 2019.

[2] G. G. Andruseac, S. V. Paturca, C. K. Banica, I. M. Costea, and C. Rotariu, "A novel method of teaching information technology applied in health monitoring," Journal of Biotechnology, vol. 239, pp. 1-2, 2016.

[3] S.-H. LEe, Y.-H. Kim, J.-K. LEe, and D. G. Lee, "Hybrid app security protocol for high speed mobile communication," The Journal of Supercomputing, vol. 72, no. 5, pp. 1715-1739, 2016.

[4] M. Danaher, K. Schoepp, and A. A. Kranov, "Schooling and measuring the professional skills of information technology students using a learning oriented assessment task," International Journal of Engineering Education, vol. 35, no. 3, pp. 795-805, 2019.

[5] Y. A. N. G. Yilong, "A study of sydney school's genre-based pedagogy in Chinese English schooling at college education," Studies in Sociology of Science, vol. 7, no. 15, pp. 6-7, 2016.

[6] C. Wang, X. Wang, J. Zhang et al., "Uncertainty estimation for stereo matching based on evidential deep learning," Pattern Recognition, vol. 124, Article ID 108498, 2021.

[7] J. V. Robotham, S. R. Deeny, C. Fuller, S. Hopkins, B. Cookson, and S. Stone, "Cost-effectiveness of national mandatory screening of all admissions to English National Health Service hospitals for meticillin-resistant Staphylococcus aureus: a mathematical modelling study," The Lancet Infectious Diseases, vol. 16, no. 3, pp. 348-356, 2016.

[8] J. G. Ross and E. Bruderle, "Student-centered teaching strategies to integrate the quality and safety education for nurses competency, safety, into a nursing course," Nurse Educator, vol. 41, no. 6, pp. 278-281, 2016.

[9] H. C. Watt, "Reflection on modern methods: statistics education beyond 'significance': novel plain English interpretations to deepen understanding of statistics and to steer away from misinterpretations," International Journal of Epidemiology, vol. 6, no. 6, pp. 6-10, 2020.

[10] N. Rose, L. Toews, and D. S. Pang, "A systematic review of clinical audit in companion animal veterinary medicine," BMC Veterinary Research, vol. 12, no. 1, pp. 40-12, 2016.

[11] K. Sattar, T. Ahmad, M. S. Khalil, M. M. Soliman, G. G. Punnamperuma, and H. M. Abdulghani, "Medical students' perception of the progress test as a quality-controlled assessment tool for improving learning and schooling, at a public sector medical college in Saudi Arabia," Journal of the Pakistan Medical Association, vol. 67, no. 2, pp. 300-304, 2017.
[12] M. E. Patrick, J. Griffin, E. D. Huntley, and J. L. Maggs, "Energy drinks and binge drinking predict college students' sleep quantity, quality, and tiredness," Behavioral Sleep Medicine, vol. 16, pp. 1-14, 2017.

[13] P. Morgenstern, R. Raslan, and G. Huebner, "Applicability, potential and limitations of staff-centred energy conservation initiatives in English hospitals," Energy Efficiency, vol. 9, no. 1, pp. 27-48, 2016.

[14] P.-C. Lee, C.-T. Lin, and H.-H. Kang, “The influence of open innovative teaching approach toward student satisfaction: a case of Si-Men Primary School," Quality and Quantity, vol. 50, no. 2, pp. 491-507, 2016.

[15] E. H. Jego and O. Amengual, "Current trends in medical English education and the Japan college of rheumatology international school," Modern Rheumatology, vol. 27, pp. 1-5, 2017.

[16] C. A. Tryon, J. T. Faith, D. J. Peppe et al., "The pleistocene prehistory of the lake victoria basin," Quaternary International, vol. 404, pp. 100-114, 2016.

[17] N. D. Roo, C. Almekinders, C. Leeuwis, and T. Tewodros, "Scaling modern technology or scaling exclusion? The sociopolitical dynamics of accessing in malt barley innovation in two highland communities in Southern Ethiopia," Agricultural Systems, vol. 174, pp. 174-175, 2019.

[18] C. Charalampous, "Katharine hodgkin (ed.), women, madness and $\sin$ in early modern england: the autobiographical writings of df, the early modern englishwoman, 1500-1750: contemporary editions (farnham: a," Medical History, vol. 60, no. 3, pp. 420-422, 2016.

[19] M. L. A. Piet, "Modern advancements in lubricating grease technology," Tribology International, vol. 97, pp. 467-477, 2016.

[20] L. Zhu and J. Xue, "Modern technology homogenizes enological traits of indigenous Saccharomyces cerevisiae strains associated with Msalais, a traditional wine in China," World Journal of Microbiology and Biotechnology, vol. 33, no. 3, pp. 63-68, 2017.

[21] A. Koc, N. Kaymakci, D. V. Hinsbergen, and L. M. V. Reinoud, "A Miocene onset of the modern extensional regime in the Isparta Angle: constraints from the Yalva Basin (southwest Turkey)," International Journal of Earth Sciences, vol. 105, no. 1, pp. 1-30, 2016.

[22] A. H. Jones and T. W. October, "Goodbye pagers, hello online platforms: embracing modern technology for communication with research participants," Pediatric Critical Care Medicine, vol. 20, pp. 20-21, 2019.

[23] Y. Zhou, "Lin Ying Constructing an innovative model of English schooling at College based on modern information technology," Northwest Medical Education, vol. 16, pp. 1262-1264, 2021. 